\title{
Increasing Inclusion or Expanding Exclusion? How the Global Strategy to Include Refugees in National Education Systems Has Been Implemented in Lebanon
}

\author{
JO KELCEY AND SAMIRA CHATILA
}

\begin{abstract}
The UNHCR strategy to include refugee students in host state education systems is intended to promote refugees' access to quality education. However, numbers of out-of-school refugees far exceed the global average. To understand these persistent barriers, we examine how Lebanese teachers and school principals understand and enact inclusion for school-age Syrian refugees. We find that inclusion has been pursued in ways that reproduce education inequities in Lebanon. Our findings underscore the importance of accounting for the internal complexities that shape the implementation and appropriation of policies within refugee host states and the ways in which these complexities interact with aid structures.
\end{abstract}

\section{Résumé}

La stratégie du HCR d'inclure les étudiants réfugiés dans les systèmes d'éducation des pays hôtes est conçue afin de

() Jo Kelcey and Samira Chatila, 2020. This open-access work is licensed under a Creative Commons Attribution-NonCommercial 4.o International Licence, which permits use, reproduction, and distribution in any medium for non-commercial purposes, provided the original authorship is credited and the original publication in Refuge: Canada's Journal on Refugees is cited. promouvoir l'accès à une éducation de qualité. Cependant, le nombre de réfugiés ne fréquentant pas l'école dépasse grandement la moyenne mondiale. Pour comprendre pourquoi, nous examinons comment les enseignants et directeurs d'écoles libanais comprennent et mettent en cuvre l'inclusion des réfugiés syriens d'âge scolaire. Nous constatons que la manière dont l'inclusion a été menée reproduit les iniquités existantes dans léducation au Liban. Nos résultats soulignent limportance de rendre compte des complexités internes qui façonnent la mise en ouvre et l'appropriation des politiques dans les pays hôtes et de la manière dont ces complexités interagissent avec les structures d'aide.

\section{Introduction}

I $\mathrm{n}$ 2012, the United Nations High Commissioner for Refugees (UNHCR) released a Global Education Strategy (GES). The GES promoted the inclusion of refugee students in host state education systems (UNHCR, 2012). Earlier, UNHCR had advocated teaching refugees their home state curriculum

Cette œuvre en libre accès fait l'objet d'une licence Creative Commons Attribution-NonCommercial 4.0 International License, laquelle autorise l'utilisation, la reproduction et la distribution de l'œuvre sur tout support à des fins non commerciales, pourvu que l'auteur ou les auteurs originaux soient mentionnés et que la publication originale dans Refuge: revue canadienne sur les réfugiés soit citée. 
in separately administered schools (UNHCR, 2012). The shift to inclusion sought to mitigate the high numbers of refugee children out of school. Specifically, it sought to expand access to education in countries of first asylum where refugees were spending increasingly long periods of time (Dryden-Peterson et al., 2019).

The approach to include refugees coincided with a sharp increase in forced displacement worldwide. The lack of formal education opportunities for refugees in many countries of first asylum has emerged as a global governance priority (Watkins \& Zyck, 2014). However, inclusion has had mixed results. Numbers of refugee children who are out of school remain much higher than average global enrolment rates, with gaps in access worsening as children get older. Only $63 \%$ of school-age refugees are enrolled in primary school, compared to $91 \%$ globally. At the secondary level, only $24 \%$ of refugees are enrolled, compared to a global average of $84 \%$ (UNHCR, 2019, p. 6). ${ }^{1}$ Inclusion has also been pursued in ways that do not always promote social cohesion (Bellino \& Dryden-Peterson, 2019; Dryden-Peterson et al., 2018). To shed light on these failings we examine how Syrian refugees have been included in Lebanese public schools. To capture the growing importance of local actors in shaping global policy, we focus on the ways in which inclusion is understood and enacted in schools. Specifically, we ask: (1) how is inclusion understood by Lebanese teachers and school principals, and (2) what factors account for these understandings?

Lebanon hosts the highest number of refugees per capita in the world, including over a million Syrians. Although Syrians can attend Lebanese public schools, $58 \%$ of school-aged Syrian children are not enrolled in formal schooling (UNHCR, 2019). Concerns have also been raised about the ways in which Syrian students are included in Lebanese public schools and the implications for social cohesion (DrydenPeterson et al., 2018; Shuayb, 2016). By examining the micro dynamics of inclusion in this context we help to unpack how UNHCR's inclusion strategy has been pursued in Lebanon and shed light on why global governance strategies pertaining to refugee education often fail to achieve their objectives.

We conducted interviews with a range of individuals working in the education sector, school-based observations, and a policy analysis. Our conceptual framework draws on the concept of cross-national policy transfer (SteinerKhamsi, 2004, 2016) and literature on how local bureaucrats (in this case, Lebanese teachers and school principals) enact and transform policy (Lipsky, 2010). We find that teachers and principals understand and enact inclusion in ways that reflect and reinforce education inequities in Lebanon. This can prevent Syrian refugees from accessing education and marginalizes refugees within the Lebanese education system.

In the next section we discuss the inclusion of refugees in host state education systems and situate our study within literature on this topic. We then present our methods, followed by our analytical approach. Our findings discuss how teachers and principals understand inclusion and the factors that shape these understandings.

\section{Inclusion as Local Practice}

In 2012, UNHCR articulated an ambitious "global education strategy" (UNHCR, 2012), which reflected the growing importance of education within refugee governance (Buckner et al., 2017) and called for refugees to be included in host state education systems. Before 2012, UNHCR pursued a "parallel system" approach, in which refugees were taught the curriculum of their countries of origin in their own language, in schools that were run by either UNHCR or its partners (UNHCR, 2015). The shift to inclusion reflected the urban and protracted character of displacement and the associated belief that allowing refugee children to attend national education systems was the best approach to education for refugee children and youth (Dryden-Peterson et al., 2019; Bellino \& Dryden-Peterson, 2019).

From the outset, the meaning of inclusion was debated. In fact the 2012-2016 GES referred to integration, not inclusion. However, the language of inclusion was soon adopted because host states were concerned that integration implied a commitment to durable solutions and the permanent resettlement of refugees within their borders. Moreover, the GES "was not intended as a global blueprint but instead as strategic objectives to be contextualized within each country" (Dryden-Peterson et al., 2019, p. 11). This has resulted in significant variation in the ways in which inclusion was understood and enacted (Dryden-Peterson et al., 2019). The importance of understanding these variations and the implications they pose for refugees' education outcomes has motivated research on the topic.

Broadly speaking, inclusion refers to the act of being included or involved within a particular group or structure. In education, Dryden-Peterson et al. (2018) conceptualize it as having structural and relational dimensions. The structural dimension refers to students' ability to access education services, while the relational dimension "is a sociocultural process related to identity development and transformation" (DrydenPeterson et al., 2018, p. 10). The different ways in which inclusion has been implemented in refugee host states reflects the range of inclusive approaches and outcomes that are possible.

1. These data include students who attend camp-based schools, not just inclusion in national education systems. 
In a multi-method cross-national study, Dryden-Peterson et al. (2019) find that the ways in which inclusion has been implemented reflect the purposes that actors at global, national, and local levels have ascribed to refugees' education. Whereas global actors based the decision to include refugees on the assumption that refugees would integrate within host states, national actors generally believed that refugees would pursue their long-term futures outside of host states. This caused tensions between global policy objectives and national outcomes (Dryden-Peterson et al., 2019). Similarly, in their examination of the gap between refugee education policy and education provisions for refugees in Lebanon, Buckner, Spencer, and Cha (2017) stress the need to understand the competing authorities that affect local decision making. In another study that examines inclusion in the Kakuma refugee camp in Kenya, Bellino and DrydenPeterson (2019) argue that inclusion is multi-directional and that for most refugees, inclusion entails "integrating down" into poorly resourced camp-based schools where they are segregated from their Kenyan peers. The authors underscore the need to distinguish between the physical and social dimensions of inclusion: the latter depends on local strategies, resources, and relationships.

We build on this work by examining how teachers and school principals understand and enact inclusion in Lebanon. Most studies of inclusion have examined it from a national vantage point (for an exception, see Bellino \& Dryden-Peterson, 2019). However, the micro dimensions of inclusion are particularly important to understand in light of the ambiguities that often characterize the implementation of global policy in nation-states (Nassar \& Stel, 2019), as well as the shift towards localization in humanitarian aid (HPG \& ICVA, 2015; UNHCR, 2017). Localization refers to the increased engagement of local actors and systems in humanitarian action. Humanitarian agencies promote localization to enhance the efficiency of aid, acknowledging the part that local actors play in responding to displacement and of the need for the humanitarian system to support them (FiddianQasmiyeh, 2018). However, localization has also been criticized as an attempt by powerful states in the Global North to shift responsibility for managing refugee crises onto host states (Fiddian-Qasmiyeh, 2018; HPG \& ICVA, 2015). In short, the implications of local actions for global policy outcomes are ambiguous and require more attention if we are to fully understand the potential of the policy to include refugees in host state education systems.

\section{Methods}

Our data come from a larger study that compares policy environments and education experiences for refugees in Australia, Turkey, and Lebanon. Here we draw on qualitative

\section{Table 1. Data Sources}

\begin{tabular}{ll} 
Data source & Description \\
\hline Syrian parents & 16 focus groups \\
Lebanese parents & 12 focus groups (with 5 to 7 people) \\
Teachers & 41 interviews \\
School principals & 15 interviews \\
Policy actors & 8 interviews \\
Policy documents & Over 10o policy documents \\
Observational data & Field notes from visits to 14 public \\
& schools across Lebanon \\
\hline
\end{tabular}

research conducted in Lebanon during the 2018/2019 academic year. We use policy documents, observations, interviews with Lebanese school principals, teachers, and policymakers, and focus group discussions with Lebanese and Syrian parents. Data were collected from 14 public schools in the five major geographical regions of Lebanon (South Lebanon, Mount Lebanon, Bekaa, Beirut, and North Lebanon). See Table 1.

Our policy analysis identified over 100 international and national policy documents in Arabic and English, pertinent to refugees' inclusion in Lebanese public schools. We used content analysis to identify the global and national vision for inclusion and to trace whether and how these visions have changed. We also carried out 16 hours of classroom observations during morning and afternoon shifts. Our observations, which were recorded in detailed field notes, capture classroom organization and management, pedagogical approaches, and student-teacher relations. Questions for the 92 semi-structured interviews and focus groups were motivated by the findings of our content analysis and included questions that were designed to elicit individuals' understandings of inclusion and the factors that shaped these understandings. All interviews were conducted in Arabic or English by five researchers between September 2018 and May 2019, recorded with participant consent, transcribed, and translated into English, where necessary.

Two researchers (the authors) coded the interviews and focus group transcripts using NVivo software. Our codes were emic (i.e., we allowed codes to emerge from our data), and etic (we also identified codes from policy documents related to inclusion). To ensure consistency and intercoder reliability, we each reviewed interviews the other had coded. The balance between inductive and deductive modes of reasoning allowed us to capture both the general (global) and context-specific (Lebanese) dimensions of inclusion. Our codes fell into five categories (1) students' family context; (2) national policy landscape; (3) teaching and learning 
environment; (4) expectations for Lebanese and Syrian students; and (5) perceptions of policy actors (governmental, United Nations, and NGO). In the sections that follow we present the conceptual framework that guided our analysis of these data.

\section{Inclusion as Policy Transfer}

Our study was motivated by literature on education policy transfer (Steiner-Khamsi, 2004, 2016) and "street-level bureaucrats" (sLBs) (Lipsky, 2010). These frameworks led us to explore how global policies shape national policies and school-level provisions, and how school interactions and practices shape and influence national and global policies. In other words, we understand refugee governance as multiscalar and multi-directional, constantly negotiated and adapted, with ambiguous implications for policy outcomes.

Literature on policy transfer is concerned with transnational governance. Emerging from scholarship on public policy and sociology, research on this topic is now a wellestablished line of inquiry across different disciplines (Delcour \& Tulmets, 2019). In comparative and international education, literature on policy transfer seeks to understand how and why education institutions, policies, and practices cross national borders (Steiner-Khamsi, 2004, 2016). However, policy transfer does not occur only between countries. Transnational organizations, including the United Nations and the World Bank, play a key role in externalizing policy by advocating good practices that are used to legitimize domestic reforms and because countries often depend on the funding that these organizations provide (Vavrus, 2004).

There are two main approaches to examining policy transfer in education literature. A neo-institutionalist perspective on policy transfer uses cross-national comparisons to examine why education structures, institutions, and policies look so similar in different countries (Meyer, Boli, Thomas, \& Ramirez, 1997; Meyer, Ramirez, \& Soysal, 1992). This contrasts with an interpretivist approach, which examines policy divergence, or why seemingly identical education policies and practices manifest differently in different countries and how this leads to different policy outcomes (Cowen, 2009; Steiner-Khamsi, 2004, 2016). A key focus of the interpretivist research has been to understand how policies are translated and adapted within nation-states.

We align with the interpretivist perspective on policy transfer since we seek to understand how inclusion has been adopted in Lebanon and why this approach has failed to significantly expand access to education as articulated in the GES. However, while much literature on policy transfer is concerned with national policy change and adaptation, we sought to bridge top-down policy and the local dynamics of inclusion (see also Hohmann, 2016). A global-local perspective on policy transfer is necessary to understand policy transfer in countries with decentralized policy structures (Hartong \& Nikolai, 2017). The local dimension of policy transfer also captures the ways in which localization and shared responsibility (which recognize and promote diverse global, national, and local actors in refugee governance; see United Nations General Assembly, 2016, 2018) affect global policy outcomes.

To this end we draw on Lipsky's (2010) theory of SLBs. This theory examines how public sector workers mediate between governments and citizens. SLBs are crucial policy actors since they are embedded in government institutions (in this case, public schools) and also exercise discretionary authority over citizens. Teachers and school principals are important SLBs because they make and enact policy in their schools and classrooms. However, the authority of SLBS is bounded by institutional and organizational constraints as well as social and cultural norms. Lipsky identifies five prominent constraints facing SLBs: inadequate resources; increased demand for services to meet supply; vague or conflicting organizational expectations and goals; challenges to measuring performance; and the fact that "clients" are captive and do not voluntarily work with SLBS (2010, p. 16). Faced with these constraints, sLBs cope in several ways: They limit demand by rationing services through preferential treatment of some groups over others (a process referred to as "creaming"); they try to induce clients to use resources in ways that achieve their particular understandings of policy; and they use their discretion to manage ambiguities and contradictions in policy goals. Although Lipsky focuses on the interactions between SLBs and citizens, the shift to inclusion means that SLBS in host states exercise considerable authority over refugees, albeit bounded by the policies in Lebanon and the norms and practices in education aid to refugees.

In the next section we present our findings. We first discuss how inclusion has been pursued in Lebanon. We highlight the tensions that emerge between the domestic policy environment and the global approach to including refugees. This has resulted in an ambiguous and contradictory policy environment for teachers and school principals. We then show how teachers and principals have used their authority to navigate these constraints with consequences for how inclusion is pursued. We conclude by discussing the implications of these findings for global policy outcomes.

\section{The Inclusion of Syrian Refugees in Lebanese Schools}

In the years since UNHCR's GES came out, the conflict in Syria has caused large-scale displacement. Over a million Syrian refugees have sought asylum in Lebanon. Since Lebanon has neither signed nor ratified the 1951 Refugee Convention, 
refugees in the country lack many legal protections, including the right to work (Aranki \& Kalis, 2014; Janmyr, 2017). Government policy on refugees is often hostile. Lebanese politicians portray the refugees as a political, social, and economic threat to Lebanon, reference the long Syrian occupation of the country, and point to the longstanding presence of Palestinian refugees in the country as reasons to reject Syrian resettlement (Chit \& Nayel, 2013; Karam, 2018). ${ }^{2}$

Compounding these challenges, public education in Lebanon is underfunded and of poor quality. For instance, teachers and school principals did not receive real wage increases for many years (Faek, 2013), while more recent economic problems have compromised the timely payment of teachers' salaries. Approximately $30 \%$ of school-age Lebanese attend public schools (the rest attend private or semiprivate schools) (MEHE-CERD, 2019). The low share of public sector enrolment has been attributed to the poor quality of public education (Shuayb et al., 2016; United Nations and Government of Lebanon, 2017). Attempts to reform the education system in 1994 and 2010 have also failed to produce meaningful change, especially in curriculum and in support for marginalized students at high risk of drop-out and failure (Shuayb, 2016). These failures reflect a policy environment beset by years of political inaction.

It is unsurprising, therefore, that the decision to include Syrian refugees occurred more by default than design-a feature of Lebanon's "no-policy policy" approach (Nassar \& Stel, 2019, p. 47). At the beginning of the refugee crisis (2011-2012), the government of Lebanon adopted a handsoff approach to the education of Syrians. Existing policies on migrant children allowed Syrian refugees to enrol in Lebanese public schools as long as the overall number of nonLebanese students did not exceed $25 \%$ of total enrolment in public schools and provided there were a minimum of 10 Lebanese students per class (see Table 2). However, there were barriers to access that resulted from complex bureaucratic processes, differences in language of instruction, and poverty. As increasing numbers of Syrians sought asylum in Lebanon, and notwithstanding the proliferation of nonformal learning opportunities, the number of out-of-school refugees became worrying (Watkins \& Zyck, 2014).

In 2013, however, the Lebanese government asserted more control over the response and began to cooperate closely with UN agencies. In 2014, the Reaching All Children with Education (RACE) I strategy was released. RACE I was a 3-year program that targeted school-aged children (3 to 18 years) affected by the Syrian crisis. The focus of this strategy was to expand access by double-shifting and contracting temporary teaching staff (Ministry of Education and Higher Education [MEHE], 2014). Double-shifting is a common response to crises. In this approach one school operates during the morning and another during the afternoon, often with different school staff. The expectation is that double-shifting will rapidly expand access to education while minimizing unit costs (Bray, 2008). This approach had an important impact. By $2016,42 \%$ of school-aged Syrian children were enrolled in Lebanese public schools (from kindergarten until grade 9) (MEHE, 2016).

Government oversight of the response has continued, although access rates for Syrian refugees have since stalled. In 2017, RACE II was launched covering 2017-2021. Led by the MEHE in close cooperation with UNICEF, it continues the focus on refugees' inclusion and calls for improved secondary and vocational education for refugees and places more emphasis on the quality of teaching and learning in public schools (MEHE, 2016). However the post-2016 period has also been marked by increasingly hostile rhetoric and a policy approach that encourages refugees to return to Syria (Nassar \& Stel, 2019). The lack of clarity about the meaning of inclusion, along with this ambiguous domestic environment, means that Lebanese teachers and principals bear responsibility for defining and implementing inclusion.

Teachers and principals held a range of views about Syrian refugees. Almost all recognized the refugees' right to education, and many also acknowledged the hardships associated with displacement. However, their views were also shaped by discriminatory public discourse and the complex and often fractious history of Syrian-Lebanese politics. In their efforts to reconcile these views with the policy to include refugees in public schools, they were also constrained by their institutional environment. Two institutional features had particular influence on their perspectives on inclusion: school finances and the proliferation of government bureaucracy.

\section{Financial Aid}

Buckner et al. (2017) argue that the decision of the Lebanese government to include refugees in public schools was driven in large part by the strong financial incentives offered by transnational aid agencies. This was apparent in our research. Teachers and principals noted that the refugee crisis had brought jobs to their communities and allowed the school to purchase materials they did not previously have. However, the fact that additional resources were available because of Syrian refugees also created tensions. Teachers and principals complained that Syrian students received support such as school stationery, free transportation, and catch-up classes from UN agencies and NGOs. In a context where Lebanese

2. Palestinian refugees predominantly attend schools run by the United Nations Relief and Works Agency for Palestine Refugees (UNRWA) or private schools. UNRWA began operating in Lebanon in 1950. 
students are also economically marginalized, and public education has been perrenially underfunded, the idea that aid was available because of Syrian students and not because Lebanese students also needed support caused many teachers and principals to resent the refugees.

Moreover, teachers and principals were very aware that the financial resources they received came from the uN, not the Lebanese government. This reinforced the view that the refugees were temporary guests to whom their responsibilities as civil servants did not extend. The following quote from a principal whose school was one of the most active in promoting activities for Syrians is indicative of the ways in which the aid binary has shaped the perspectives of teachers and principals on inclusion:

Refugees are the only beneficiaries from this integration [inclusion]. The only benefit for the Lebanese is that young Lebanese people now have a new job opportunity, which is teaching in the afternoon. Now our refugee students are $100 \%$ integrated at our school. Any activity the school does, they are included in it. Refugees don't have any activities, but we created some for them. We let them plant in the garden and we organize football matches during recess time. We also integrate morning and afternoon shift students at 2:30 p.m. and do "crazy science" 3 at 2:30 p.m. for students of both shifts, together. On children's day, I hung pictures of both morning and afternoon shift students.

This quote captures a view expressed by many teachers and principals: that the schools belonged first and foremost to the Lebanese, who allowed the Syrians to attend. It illustrates how aid that was tied to the refugees' attendance at school reinforced the binary of refugees versus nationals and promoted a view of inclusion as a uniquely structural concept that did not extend to Syrians' right to fully participate in school life.

\section{Bureaucratic Proliferation}

We also found that teachers and principals were overwhelmed by the proliferation of government bureaucracy related to Syrian refugees. As noted above, in the early years of the crisis, the government had largely absented itself from decision making. In the years since, however, the government has engaged in "a paradoxical mixture of extremely stringent and changeable regulations that were not transparently communicated to either the public or humanitarian and development partners and that were enforced in a fickle and arbitrary manner" (Nassar \& Stel, 2019, p. 47). One principal told us that he received policy decisions, memos, circulars, and announcements from the MEHE "every 1 week or 10 days, and sometimes up to 15 days." "Decisions change all the time," he added, and were often "impulsive" (see Table 2). We sought to identify how the MEHE determines priorities for student enrolment. Before 2011, the main criteria for determining the priority accorded to students' request to enrol in a public school were their academic performance and whether or not they had previously attended a public, private, or other school (such as an UNRwA school). The table shows how criteria for determining students' inclusion have rapidly increased since 2011. Principals must now consider students' and parents' nationality and gender, ${ }^{4}$ and students' academic performance and former school status to determine what priority to accord their enrolment. This bureaucratic proliferation and the ad hoc policymaking that contributes to it reflect the short-term vision of the refugees' presence in the country.

Significantly, this process takes place in the context of double-shifting, in which a small number of Syrians are allowed to attend the first shift alongside Lebanese, a much larger group of Syrians are assigned to the second shift, and an even larger number of students cannot access public schools at all. Different resources and perceptions of quality are associated with the first and second shifts. The first shift is staffed by tenured teachers and is perceived as offering a better quality of education than the second shift (Shuayb et al., 2016). When resources are constrained, the fragmentation and differentiation of education opportunities across shifts, as well as the inability of the system to cater to all refugees, means that this method of determining inclusion paradoxically produces several forms of exclusion. This finding aligns with Bellino and Dryden-Peterson's concept of downward integration, in which education settings do not necessarily promote the upward mobility of refugees within host state societies but instead integrate them down into vulnerability and marginalization (2019). In the following section we discuss how teachers and principals use their discretionary power to negotiate these complex, ambiguous, and often contradictory policy processes.

\section{Negotiating Inclusion Through Teacher and Principal Discretion}

Like all SLBs, Lebanese teachers and principals adopt coping strategies to manage institutional constraints. They limit demand through preferential treatment of some groups over others, they use resources to pursue their particular understandings of policy, and they use discretion to manage

3. "Crazy science" relates to fun and interactive science activities.

4. Lebanese women are unable to confer nationality on their children. A child born of a Lebanese mother and a non-Lebanese father is therefore classified by government institutions as non-Lebanese and treated differently from Lebanese nationals. 
Table 2. Priority Categories for Student Enrolment in the First Shift of Lebanese Public Schools (Where 1 Is the Highest Priority and 20 the Lowest)

Timeframe Priority categories

Priority categories 1. Students who received a passing grade in the previous academic year (MEHE, 2001)

before 20112 2. School students who failed the academic year but were accepted to repeat their classes (MEHE, 2001)

3. New students from other public schools, who are promoted to higher academic years (MEHE, 2001)

4. New students from other public schools who failed (MEHE, 2001)

5. New students from other (non-public) schools, who are promoted to higher academic years (MEHE, 2001)

Categories added

(2011-2017)
6. Lebanese students (old and new) (MEHE, 2017b)

7. Lebanese students (old and new) who have missed the first deadline for registration (if deadline extensions were made) (MEHE, 2017a)

8. Non-Lebanese students (old and new) whose mother is Lebanese (Lebanese Forces, 2017; MEHE, 2017a)

9. Non-Lebanese students who were enrolled in the morning shift of public schools for more than three years and have a certified school attestation (Lebanese Forces, 2017; MEHE, 2017a)

10. Palestinian students living in Lebanon since before the Syrian crisis in regions where there are no UNRWA schools and who were not enrolled in any UNRWA schools last year (Lebanese Forces, 2017; MEHE, 2017a)

11. Non-Lebanese students (old and new) originating from countries that do not suffer from a displacement crisis (Lebanese Forces, 2017; MEHE, 2017a)

12. Siblings of non-Lebanese students who were accepted on the basis of the above priorities, as long as they do not fulfill the criteria below (Lebanese Forces, 2017; MEHE, 2017a)

(cont'd next page)

ambiguities and contradictions in policy goals. This has manifold consequences for students.

For example, one principal who was overwhelmed by the number of Syrian students attending his school told us that when the numbers of Syrians who enrolled did not decline during last academic year, he started to expel them. Similarly, another principal reported that she did not allow any nonLebanese children (with the exception of those who had a Lebanese mother) to attend the morning shift and sent them to other public schools because "at the end of the day, it is the Lebanese student's right to get in first."

Other examples were more ambiguous. We found that teachers and principals often prioritized the highestachieving Syrians for the first shift, while claiming that Syrian students in general exhibited difficult behaviour and thus needed to be separated from their Lebanese peers. While we do not wish to minimize the many challenges that Syrian learners face in language of instruction, differences in curricula content, poverty, and the precarity of their legal status, the claims that teachers and principals made about the academic performance and behaviour of most Syrian students were strikingly at odds with our observations, during which we recorded high levels of engagement and attentiveness among Syrian students, in spite of overcrowded classrooms.

Nor was it uncommon for teachers and principals to contradict themselves during their interviews. After arguing that students in the morning shift were more academically capable, one principal backtracked and stated, 
Table 2 (cont'd)

Recently added categories

(2018-present)
13. Lebanese students (old and new), including Lebanese students coming from Syria) (MEHE, 2018b)

14. Lebanese students who have missed the first deadline (if deadline extensions were made) (MEHE, 2018a, 2018c)

15. Non-Lebanese students (old and new) whose mother is Lebanese (MEHE, 2018a, 2018c, 2019)

16. Non-Lebanese students who were enrolled in the morning shift of public schools for more than three years and have certified school attestation (MEHE, 2018a, 2018c, 2019)

17. Palestinian students living in Lebanon since before the Syrian crisis in regions where there are no UNRWA schools and who were not enrolled in any UNRWA schools last year (MEHE, 2018a, 2018c, 2019)

18. Non-Lebanese students (old and new), originating from countries that do not suffer from a displacement crisis (MEHE, 2018a, 2018c)

19. Siblings of non-Lebanese students who were accepted on the basis of the above priorities, as long as no new sections are created as stated below (MEHE, 2018a, 2018c, 2019)

20. All other new students bearing in mind the following:

- Article 1 of Decree No. 1049/2018: Under no circumstances shall the number of non-Lebanese students in kindergarten exceed $25 \%$ of the total number of students in class (Lebanese Forces, 2017; MEHE, 2018a, 2018c, 2019)

- Article 2 of Decree No. 1049/2018: Non-Lebanese students, despite fulfilling the above priorities, can be enrolled only under the condition of having no less than ten Lebanese students, and with the consequent illegal creation of sections by allowing the registration of non-Lebanese students under any circumstances (Lebanese Forces, 2017; MEHE, 2018a 2018c 2019)
[The Syrians] are not less productive. The percentage of them passing the ninth grade is equal to those of the morning shift. We have no problem there, but there is a high number of drop-out students. Students might enrol for 2, 3 weeks and then disappear. When we ask about them, we discover that they have either moved to Syria or joined the labour force at 9 or 10 years old.

His response illustrates a broader trend we observed in which levels of perceived vulnerability became the basis upon which Syrians were selected for inclusion in the first shift, or exclusion into the segregated second shift. This "creaming" has important consequences, since access to the first shift provides Syrian students with acceptance and inclusion within Lebanese society, while access to the second shift tends to reify differences and inequalities between Lebanese and Syrians as well as among Syrians. As one principal commented, "Those [Syrians who attend the first shift] have become so well integrated that they now see themselves as different from the Syrian students in the afternoon shift."

There were also important examples of teachers and principals who sought to circumvent official policy to be more inclusive of Syrians. Several principals relaxed official enrolment requirements to accommodate Syrian students, while one school created a parent-teacher council for Syrian parents. This initiative was notable because these councils are not legally required for Syrian parents (as they are for Lebanese), even though clear and transparent communications between families and schools was a priority for the Syrian parents we spoke with.

Yet even these efforts were constrained by the temporary and conditional nature of Syrian asylum in Lebanon. A teacher captured this when he told us,

We are Lebanese people. When Syrians came to us with difficult conditions, we accepted them, of course, as our brothers in humanity, and a lot of help took place. But at the end, just as you say "me," it's also "my" country. Do you understand? I'm not saying anythingthey're welcomed-but they have their country and we have ours. They have difficult circumstances and they came here, we welcomed them. But at the end, everything has to end. Everything has to end.

Syrians' dependence on the financial support of aid agencies, as well as the contested vision for inclusion among global and national actors has contributed to this local shortterm and contingent logic of inclusion. 


\section{Conclusion}

The decision to include refugees in host state education systems marked a profound shift in UNHCR education policy. This policy was intended to improve access to education and support the integration of refugees into host state societies. However, large numbers of refugees remain out of school, and prospects for their social integration are limited. To shed light on this discrepancy, we examined how inclusion has been implemented in Lebanon. Drawing on the concept of policy transfer, we argued that the outcomes of policies toward refugees are the result of negotiations between global, national, and local actors that result in the convergence of policy across contexts. We further argued that it was important to examine local policy and the behaviour of teachers and principals who act as "street-level bureaucrats" (Lipsky, 2010) to better account for divergences between global policy objectives and outcomes.

We found that inclusion in Lebanon is a predominantly structural phenomenon, which results in the downward integration of refugees by providing access to education opportunities that are of poorer quality than those provided to host state nationals (see also Bellino \& Dryden-Peterson, 2019; Dryden-Peterson et al., 2018; Dryden-Peterson et al., 2019). We also showed how ostensible inclusion generates exclusion, as local actors are forced to prioritize and distribute scarce resources and navigate ambiguities between global ideals and national realities. The institutional and organizational constraints that teachers and principals worked under caused them to stratify students primarily on the basis of academic performance and socio-economic vulnerability. Yet these were precisely the sources of inequality that have marginalized Lebanese students in public schools from their Lebanese peers in private schools.

Thus while inclusion is the stated intention of the GES, the misalignment of the GES and the ambiguous domestic policy environment in Lebanon has resulted in the stratification of both refugee and Lebanese public school students. Teachers and principals view Syrians as temporary guests, and thus their actions as street-level bureaucrats reshape inclusion to better meet their needs as well as those of Lebanese students who have long been marginalized within the Lebanese education system. In this way, our findings underscore the importance of defining a clear vision for inclusion and accounting for the internal contradictions of host states when formulating education policies for refugees. More generally, global policies and aid structures need to be flexible enough to respond to the structural shortcomings of host state public services.

\section{References}

Aranki, D., \& Kalis, O. (2014, September). Limited legal status for refugees from Syria in Lebanon. Forced Migration Review, 47, 17-18. https://www.fmreview.org/syria/ aranki-kalis

Bellino, M. J., \& Dryden-Peterson, S. (2019). Inclusion and exclusion within a policy of national integration: Refugee education in Kenya's Kakuma refugee camp. British Journal of Sociology of Education, 40(2), 222-238. https:// doi.org/10.1080/01425692.2018.1523707

Bray, M. (2008). Double-shift schooling: Design and operation for cost-effectiveness (3rded.).Paris: UnEsco, International Institute for Educational Planning. https://www.oecdilibrary.org/content/publication/9781848597280-en

Buckner, E., Spencer, D., \& Cha, J. (2017). Between policy and practice: The education of Syrian refugees in Lebanon. Journal of Refugee Studies, 31(4), 444-465. https:// doi.org/10.1093/jrs/fexo27

Chit, B., \& Nayel, M. A. (2013). Understanding racism against Syrian refugees in Lebanon. Beirut: Civil Society Knowledge Centre, Lebanon Support. https://civilsociety-centre.org/paper/understanding-racism-against-syrian -refugees-lebanon

Cowen, R. (2009). The transfer, translation and transformation of educational processes: and their shape-shifting? Comparative Education, 45(3), 315-327. https://doi. org/10.1080/03050060903184916

Delcour, L., \& Tulmets, E. (2019). Introduction. In L. Delcour \& E. Tulmets (Eds.), Policy transfer and norm circulation: Towards an interdisciplinary and comparative approach (pp. 1-16). ProQuest Ebook Central.

Dryden-Peterson, S., Adelman, E., Alvaradoa, K. A., Bellino, M. J., Brooks, R., Unsa, S. S., Caoa, E., Chopra, V., Faizia, Z., Gullaa, B., Maaroufa, D., Reddick, C., Scherrera, B., Smoake, E., \& Suzukia, E. (2018). Inclusion of refugees in national education systems. Background paper prepared for the 2019 Global Education Monitoring Report. Migration, displacement and education. Building bridges not walls. Paris: UNESCO, Global Education Monitoring report.

Dryden-Peterson, S., Adelman, E., Bellino, M., \& Chopra, V. (2019). The purposes of refugee education: Policy and practice of including refugees in national education systems. Sociology of Education, 92(4), 1-21. https://doi. org/10.1177/0038040719863054

Faek, R. (2013, March 19). Paralyzing strike in Lebanese public education ends. Al-Fanar Media. https://www. al-fanarmedia.org/2013/03/paralyzing-strike-ripplesthrough-lebanese-public-education/

Fiddian-Qasmiyeh, E. (2018, April 17). The localisation of aid and southern-led responses to displacement: Beyond instrumentalising local actors. Refugee Hosts. https:// 
refugeehosts.org/2018/04/17/the-localisation-of-aidand-southern-led-responses-to-displacement/

Hartong, S., \& Nikolai, R. (2017). Observing the "local globalness" of policy transfer in education. Comparative Education Review, 61(3), 519-537. https://doi. org/10.1086/692503

Hohmann, U. (2016). Making policy in the classroom. Research in Comparative \& International Education, 11(4) 380-393. https://doi.org/10.1177/1745499916679561

Humanitarian Practice Group and ICVA. (2015). Localisation in humanitarian practice. https://www.icvanetwork.org/ system/files/versions/ICVA_odi_Localisation_paper.pdf

Janmyr, M. (2017). No country of asylum: "Legitimizing" Lebanon's rejection of the 1951 Refugee Convention. International Journal of Refugee Law, 29(3), 438-465. https://doi.org/10.1093/ijrl/eexo26

Karam, J. (2018, September 25). Gebran Bassil: Lebanon does not accept Syrians as "refugees." National News. https:// www.thenationalnews.com/world/gebran-bassillebanon-does-not-accept-syrians-as-refugees-1.773658

Lebanese Forces. (2017). Hamadeh: Non-Lebanese students start enrolling in public schools. https://www.lebaneseforces.com/2017/o9/19/marwan-hmede-41/

Lipsky, M. (2010). Street-level bureaucracy, 3oth anniversary edition: Dilemmas of the individual in public service. Russell Sage Foundation. ProQuest Ebook Central.

Meyer, J., Boli, J., Thomas, G., \& F. Ramirez. (1997). World society and the nation-state. American Journal of Sociology, 103(1), 144-181. https://doi.org/10.1086/231174

Meyer, J., Ramirez, F., \& Soysal, Y. (1992). World expansion of mass education, 1870-1980. Sociology of Education, 65(2), 128-149. https://doi.org/10.2307/2112679

Ministry of Education and Higher Education (MEHE). (2001). Decree no. $1130 / \mathrm{m} / 2001$ regarding rules of procedure for official kindergarten and basic education schools. Lebanon: Ministry of Education and Higher Education.

Ministry of Education and Higher Education (MEHE). (2014). Reaching all children with education in Lebanon (RACE). Lebanon: Ministry of Education and Higher Education. https://www.mehe.gov.lb/ar/Projects/ماعل20\%ميلعتل/20 RACEfinalEnglish2.pdf

Ministry of Education and Higher Education (MEHE). (2016). Reaching all children with education (RACE II). (20172021). Lebanon: Ministry of Education and Higher Education. nu-47/race2-articleNorwegian Refugee Council. (2020)

Ministry of Education and Higher Education (MEHE). (2017a). Decree no. 802 regarding the extension of registration for the academic year 2017/2018 and the acceptance of the registration of non-Lebanese students in public schools in the morning shift. Lebanon: Ministry of Education and Higher Education.

Ministry of Education and Higher Education, Lebanon (MEHE). (2017b). Memo no. 107 on the start of the academic year and the organization of student enrolment and registration in the official kindergarten and primary schools for the academic year 2017/2018. Lebanon: Ministry of Education and Higher Education.

Ministry of Education and Higher Education, Lebanon (MEHE). (2018a). Decree no.1049/2018 regarding the extension of registration period for the academic year 2018/2019 and the admission of non-Lebanese students in public schools during the morning shift. Lebanon: Ministry of Education and Higher Education.

Ministry of Education and Higher Education, Lebanon (MEHE). (2018b). Memo no. 87 on the start of the academic year and the organization of student enrolment and registration in the official kindergarten and primary schools for the academic year 2018/2019. Lebanon: Ministry of Education and Higher Education.

Ministry of Education and Higher Education, Lebanon (MEHE). (2018C). Memo no. 59 on the amendment of article no. 2 of decision no. 1049/m/2018 on 26/9/2018. Lebanon: Ministry of Education and Higher Education.

Ministry of Education and Higher Education, Lebanon (MEHE). (2019). Decree no. 570/m/2019 regarding the admission requirements of non-Lebanese students to public schools for the academic year 2019/2020. Lebanon: Ministry of Education and Higher Education.

Ministry of Education and Higher Education, Lebanon, Centre for Educational Research and Development (MEHE-CERD). (2019). Statistical bulletin of scholastic year 2018-2019. https://www.crdp.org/sites/default/ files/2019-11/1_1.pdf

Nassar, J., \& Stel, N. (2019). Lebanon's response to the Syrian refugee crisis: Institutional ambiguity as a governance strategy. Political Geography, 70, 44-54. https://doi. org/10.1016/j.polge0.2019.01.005

Shuayb, M. (2016). Education for social cohesion attempts in Lebanon: Reflections on the 1994 and 2010 education reforms. Education as Change, 20(3), 225-242. https:// doi.org/10.17159/1947-9417/2016/1531

Shuayb, M., Al Maghlouth, N., Held, K., Ahmad, N., Badran, T., \& Al Qantar, S. (2016). An education for the future: The schooling experience of Syrian refugee children in Lebanon and Germany. Beirut: Centre for Lebanese Studies. Steiner-Khamsi, G. (2004). Globalization in education: Real or imagined? In G. Steiner-Khamsi (Ed.), The global politics of educational borrowing and lending (pp. 1-6). New York: Teachers College Columbia. 
Steiner-Khamsi, G. (2016). New directions in policy borrowing research. Asia Pacific Education Review 17, 381-390. https://doi.org/10.1007/s12564-016-9442-9

United Nations and Government of Lebanon. (2017). Lebanon crisis response plan 2017-2020. Part II: Operational response plans: Education. https://www.un.org.lb/ library/assets/Education-015415.pdf

United Nations General Assembly. (2016). New York Declaration for Refugees and Migrants. https://www.un.org/ en/development/desa/population/migration/generalassembly/docs/globalcompact/A_RES_71_1.pdf

United Nations General Assembly. (2018). Global compact on refugees. In Report of the United Nations High Commissioner for Refugees: General Assembly official records seventy-third session supplement no. 12. Part II. New York: United Nations. https://www.unhcr.org/gcr/ GCR_English.pdf

UNHCR. (2012). Education strategy 2012-2016. Geneva: UNHCR. http://www.unhcr.org/5149ba349.html

UNHCR. (2015). Curriculum choices in refugee settings. Issue brief 3. Geneva: UNHCR.

UNHCR. (2017). UNHCR's strategic directions 2017-2021. Geneva: UNHCR. http://www.unhcr.org/5894558d4.pdf
UNHCR. (2019). Education programme. https://www.unhcr. org/lb/wp-content/uploads/sites/16/2019/o4/Education-Factsheet.pdf

Vavrus, F. (2004). The referential web: Externalization beyond education in Tanzania. In G. Steiner-Khamsi, The global politics of educational borrowing and lending (pp. 141-153). New York: Teachers College Columbia.

Watkins, K., \& Zyck, S. (2014). Living on hope, hoping for education: The failed response to the Syrian refugee crisis. London: Overseas Development Institute. https://www. odi.org/sites/odi.org.uk/files/odi-assets/publicationsopinion-files/9169.pdf

Jo Kelcey is a post-doctoral fellow in the Department of Education at the Lebanese American University. She can be reached at joalix.kelcey@lau.edu.lb.

Samira Chatila is a doctoral student at the University of Minnesota (UMN), and a fellow in the Interdisciplinary Center for the Study of Global Change at UMN. She can be reached at chatioos@umn.edu. 